Nat. Hazards Earth Syst. Sci., 18, 397-403, 2018

https://doi.org/10.5194/nhess-18-397-2018

(C) Author(s) 2018. This work is distributed under the Creative Commons Attribution 4.0 License.

\title{
Brief communication: Post-seismic landslides, the tough lesson of a catastrophe
}

\author{
Xuanmei Fan, Qiang Xu, and Gianvito Scaringi \\ The State Key Laboratory of Geohazards Prevention and Geoenvironment Protection (SKLGP), \\ Chengdu University of Technology, Chengdu, Sichuan, 610059, China
}

Correspondence: Qiang Xu (xuqiang_68@126.com) and Gianvito Scaringi (g.scaringi@qq.com)

Received: 13 October 2017 - Discussion started: 18 October 2017

Accepted: 17 December 2017 - Published: 26 January 2018

\begin{abstract}
The rock avalanche that destroyed the village of Xinmo in Sichuan, China, on 24 June 2017, brought the issue of landslide risk and disaster chain management in highly seismic regions back into the spotlight. The long-term postseismic behaviour of mountain slopes is complex and hardly predictable. Nevertheless, the integrated use of field monitoring, remote sensing and real-time predictive modelling can help to set up effective early warning systems, provide timely alarms, optimize rescue operations, and perform secondary hazard assessments. We believe that a comprehensive discussion on post-seismic slope stability and on its implications for policy makers can no longer be postponed.
\end{abstract}

\section{Introduction: the 2017 Xinmo landslide, the lasting legacy of earthquakes}

On 24 June 2017, after days of not-so-heavy rain, a 13 million $\mathrm{m}^{3}$ rock and debris avalanche submerged the village of Xinmo (in the eastern margin of the Tibetan Plateau, Sichuan, China) with impressive energy, rushing towards the river and blocking its course for more than $1 \mathrm{~km}$. The rescue operations were launched promptly, and all possible efforts were done by local heroes and professionals. Nonetheless, 10 people were found dead and a further 73 were reported missing in one of the deadliest landslides in recent history (Fan et al., 2017; Fig. 1).

Almost a century earlier, in 1933, Xinmo was struck by a magnitude $M_{\mathrm{s}} 7.5$ earthquake, during which large-scale landslides destroyed villages and choked rivers, producing dammed lakes that, collapsing, produced enormous floods, killing thousands of people (Cheng et al., 2008). Many co- seismic landslides left large amounts of loose material along the slopes which, in turn, caused deadly debris flows and avalanches during every rainy season for decades - just like what happened, and is still happening, after the $M_{\mathrm{S}} 8.02008$ Wenchuan earthquake (Fan and Huang, 2013), not far away. However, what does not collapse during the quake is not exempt from damage. An earthquake can produce cracks and fractures in the rock which, paradoxically, can be noticed from space by satellites but yet hidden to the human eye if covered by dense vegetation on high-elevation ridges (e.g. Fan et al., 2017). The damaged rock can hold in place for decades or even centuries, but rainwater can infiltrate within the fractures, dissolve minerals, fill the cracks, freeze, and pull the blocks apart with its pressure until, more or less suddenly, the proverbial last straw - a rainfall or a minor shake (Qiu, 2016) - makes it collapse.

The long-term effect of strong earthquakes on the geological hazards in mountainous areas seems to be an underestimated issue. While coseismic landslides are well described (e.g. Parker et al., 2011; Zhang et al., 2016), and large attention is being given to the short and mid-term effects of earthquakes on debris flow occurrence and sediment yield (Hovius et al., 2011), the delayed effects on slope stability is often neglected. Rock weathering and crack propagation are complex time-dependent processes. Thus, the occurrence of post-seismic landslides does not follow a clear trend, and destructive events might happen "randomly", decades after the quake (see Towhata, 2013). Rock slopes damaged by the $M_{\mathrm{w}} 7.7$ Chi-Chi earthquake in 1999 in Taiwan (Lin et al., 2006) are still collapsing, year after year during the rainy seasons, causing hundreds of fatalities. Post-seismic landslides and long-term rock degradation have been reported in several 


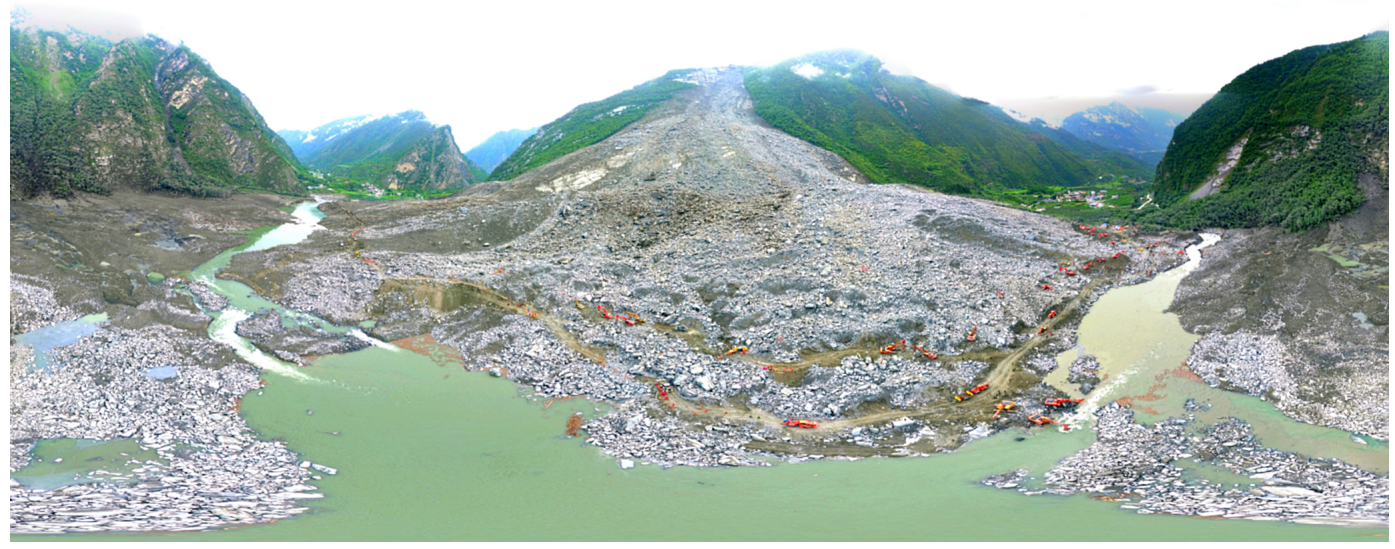

Figure 1. Panoramic view of the Xinmo rock avalanche as seen from the opposite slope. Notice the red trucks for the scale.

areas of Japan (Okamoto et al., 2012), and a clear tendency for landslides to occur more frequently due to past earthquakes has been found in New Zealand (Parker et al., 2015). Several recent landslides in Sichuan, China, have been correlated with the $M_{\mathrm{s}} 7.5$ Xichang earthquake (Wei et al., 2014), which occurred more than 160 years ago.

It is estimated that 5000 to 10000 die because of a noncoseismic landslide each year in the world, with China being the most exposed country (Petley, 2012) and with a worrisome increasing trend over time. A significant number of events can be regarded as post-seismic landslides, such as the recent one in Xinmo, for which the rock weakening action of past strong earthquakes likely acted as a predisposing factor.

\section{An example of policy: disaster prevention and emergency response in China}

China has been doing great efforts in funding research, allocating special budget to professional teams and training the general public and government divisions at various levels with the aim of improving early reconnaissance, warning, and prevention of geological hazards. Nevertheless, tragedies still happen and, unfortunately, the Xinmo landslide was not an isolated event. In 2013, the Wulipo landslide - an event with similar characteristics - claimed 166 victims. It was considered as a lagged effect of the 2008 Wenchuan earthquake (Yin et al., 2016). According to Huang (2009), most of the catastrophic landslides in China might be caused by the joint effect of earthquakes and rainfall (Huang, 2009).

On the other hand, China has gained solid experience in the emergency response and rescue in catastrophic events.
With the leitmotif "safety first", the government listed disaster prevention and reduction in its economic and social development plan as an important guarantee of sustainable development. One year after the 2008 Wenchuan earthquake, with the white paper "China's Actions for Disaster Prevention and Reduction", the State Council defined the strategic goals and tasks of disaster reduction and built a legal framework, an institutional setup, and an operative mechanism for disaster reduction (Chinese Government, 2009). To strengthen the capacity of emergency rescue and relief work, the National Emergency Plan for Sudden Geological Disasters was also enforced, featuring centralized command, sound coordination, clear division of tasks, and level-by-level control with local authorities. The geo-disasters have been classified into four size-dependent categories according to the estimated fatalities and money loss (Fig. 2). Different levels of government have been given responsibility for handling disasters of different magnitude.

In the wake of a highly catastrophic event, the local-level divisions are required to report to the State Council directly within no more than $4 \mathrm{~h}$, and the latter will take immediate action. The commanding and coordination headquarters, led by the State Council directly, will be set up with a crossfunctional steering committee, consisting of experts from different fields, to conduct rescue work, evacuation, temporary relocation, information and data gathering, geological surveying, weather forecasting, medical and epidemic prevention, lifeline engineering repair, and so on. The headquarters have also the power to command the People's Armed Police (the Chinese army) directly. Conversely, in the case of smalland medium-scale disasters, the local government will trigger the emergency response immediately and autonomously 


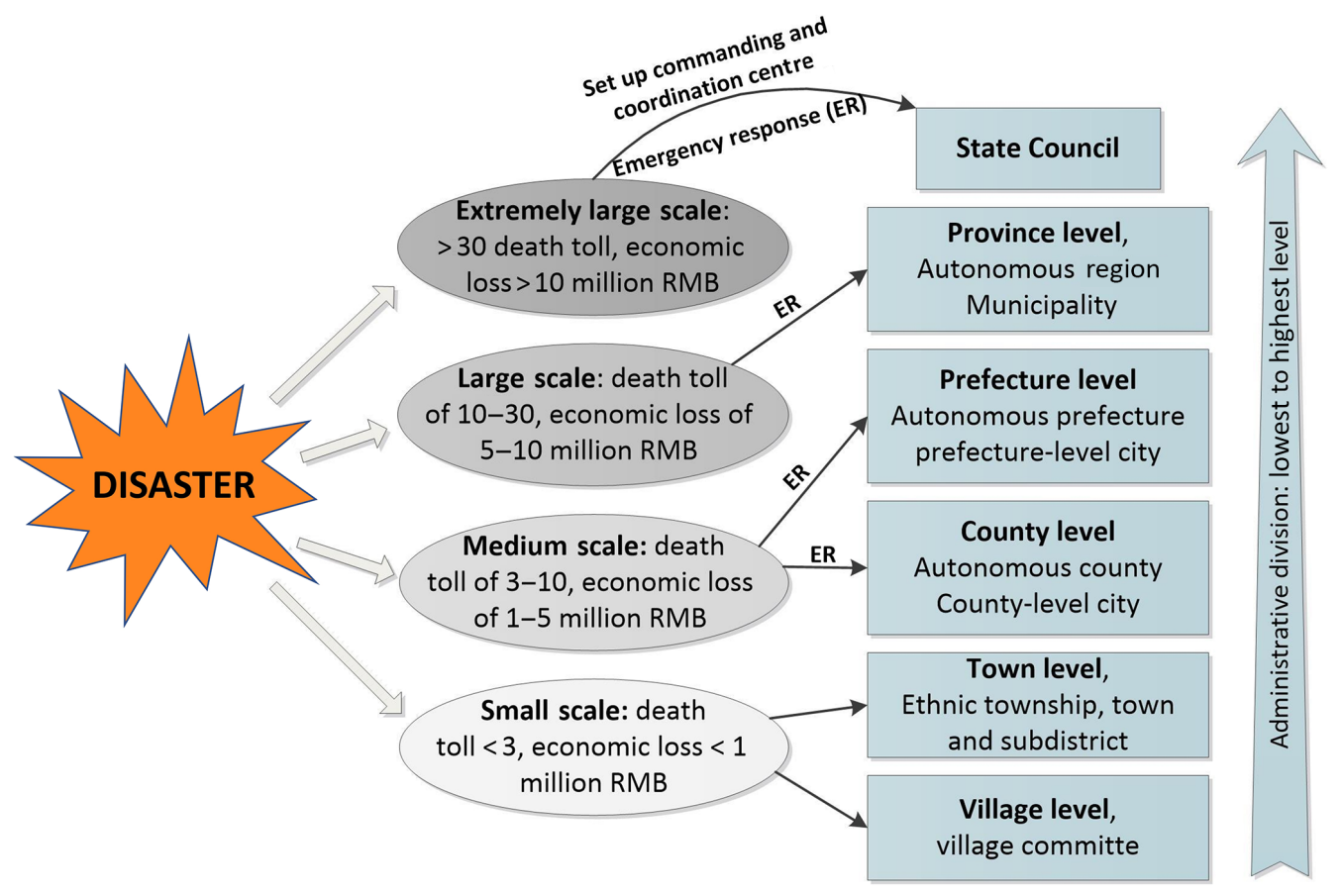

Figure 2. The emergency response to disasters in the People's Republic of China.

and will set up a local emergency command, with the local government's heads serving as chief commanders, to jointly set up the emergency response and disaster relief, organize the field work, and report on the disaster details and work progress to the higher governmental level.

\section{Open discussion: the lesson of a killer landslide}

The recent catastrophic event in Xinmo received considerable attention by the scientific community and by the media worldwide, bringing the issue of landslide risk and disaster chain management in highly seismic regions back into the spotlight. Through this brief, work-in-progress paper, we hope to trigger a comprehensive open discussion within the scientific community and gather and share ideas on the best handling of long-term post-seismic slope stability problems and on its implications for policy makers.

Soon after the Xinmo landslide, the Sichuan Province Administration began a detailed investigation to identify potential geohazards before the beginning of the rainy season. The satellite radar interferometry technique (InSAR) has been applied to identify hot spots of deformation within the large search region. Laser scanning (lidar) and drone flights (UAV) were then been used to further confirm the potential hazardous sites. We think that this is perhaps the most effective way to proceed in densely vegetated mountainous areas. Satellite images of the Xinmo village in the visible spectrum taken subsequent to 2003 showed that there were indeed several cracks, up to $150 \mathrm{~m}$ long and interconnected to some extent, in the landslide source area (Fan et al., 2017). InSAR images highlighted noticeable deformations (Fig. 3a, b) in the rock mass during the months preceding the landslide and, reasonably, the infiltration of recent rainfalls within the cracks speeded up the failure process (Fan et al., 2017).

Tragedies such as the one occurred in Xinmo might be avoided if the same scrupulous and systematic early reconnaissance and monitoring activity is carried out in due time. Satellite imagery can help detect and prioritize potential hazardous areas. Then, through field and aerial investigations, using UAV, lidar, and InSAR, detailed mapping can be done. Potentially critical situations can be recognized and then handled through continuous monitoring of deformations, for instance through ground-based SAR interferometry (Crosetto et al., 2014; Monserrat et al., 2014; Fan et al., 2017). Furthermore, in situ recording and interpretation of the characteristics of ambient noise, i.e. the low energy and low-frequency vibrations of the ground due to natural or anthropic sources (e.g. Del Gaudio, 2017), can be used to characterise the mechanical properties of the soil or rock mass (e.g. anisotropy, sets of directional discontinuities; Di Giulio et al., 2009) and their changes with time (e.g. shear wave velocity decrease due to crack opening or water level rise; Daskalakis et al., 2016; Behm, 2016), potentially providing an indirect assessment of strength degradation or stress changes. Furthermore, monitoring of acoustic emissions, i.e. the high-frequency transient elastic waves originating from the sudden release of energy at localized points within a loaded material (Nomikos et al., 2010), can provide information on the occurrence of microcracks within the rock, that may signal progression of 

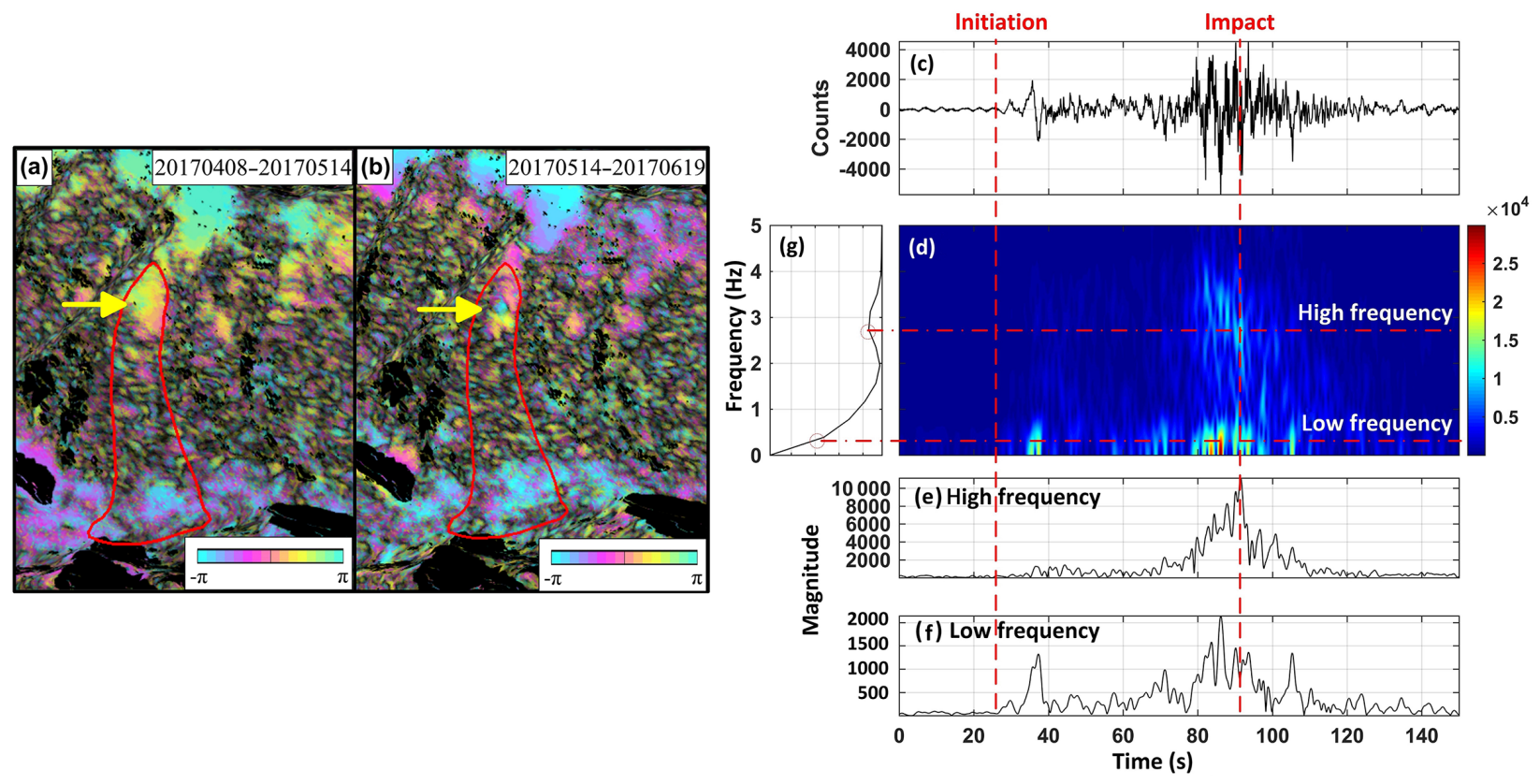

Figure 3. (a, b) Differential interferogram of the landslide obtained by processing Sentinel-1 satellite data. The arrow points to the deformation occurred in the landslide source area. (c-g) Seismic signal of the Xinmo landslide event recorded by the Maoxian MXI station, about $43 \mathrm{~km}$ apart (modified from Fan et al., 2017): vertical component (c); frequency-time Hilbert spectrum (d); high-frequency time-magnitude spectrum, $f=2.73 \mathrm{~Hz}$ (e); low-frequency time-magnitude spectrum, $f=0.4 \mathrm{~Hz}$ (f); frequency-magnitude spectrum (g).

rock damaging, crack coalescence, deformations, and incipient failure (e.g. Manthei and Eisenblätter, 2008; Agioutantis et al., 2016). Such techniques, combined with hydrological monitoring, would be extremely valuable for setting up early warning systems and help the authorities to take informed decisions on possible evacuation or relocation of the exposed people.

In addition, if the event happens too suddenly to take countermeasures, something could still be done to optimize the alarm-and-rescue chain, for instance, by using the existing seismic networks. In fact, it is known that landslides generate seismic signals, "landquakes", which contain a specific signature: low-frequency waves released by the bedrock when the mass detaches, and high-frequency waves produced by the landslide mass while it is sliding, peaking when it impacts the deposition area (e.g. Yamada et al., 2012; Chen et al., 2013). If analysed separately, they can give information on both landslide initiation and impact (Fig. $3 \mathrm{c}-\mathrm{g}$ ). In theory, two distinct epicentres can be identified automatically by the seismic networks, if they are sensitive enough and they are taught to do so. In the case of the Xinmo landslide, the seismic recording showed that just 1 min elapsed from the initiation to the deposition, during which the mass slid along the slope for more than $2.5 \mathrm{~km}$, with more than $1000 \mathrm{~m}$ of height relief, and hit the population at an impressive velocity $v=250 \mathrm{~km} \mathrm{~h}^{-1}$ (Fan et al., 2017, following Lin, 2015). The potential energy released by the event could be estimated, $E=290 \mathrm{TJ}$ (Fan et al., 2017, following Lin et al., 2015), and thus the volume involved, $V=13$ million $\mathrm{m}^{3}$ (quite close to the estimation based on field observation and topographic difference), and the average mobilized friction coefficient, $\mu=0.29$ (following Lin, 2015). For comparison, similar evaluations resulted in $E=150 \mathrm{TJ}, \mu=0.12$, $v=298 \mathrm{~km} \mathrm{~h}^{-1}$, and $V=10^{7} \mathrm{~m}^{3}$ for the 2009 Hsiaolin landslide in Taiwan (Lin et al., 2010, 2015; Lin, 2015), and $E=55 \mathrm{TJ}, v=101 \mathrm{~km} \mathrm{~h}^{-1}$ and $V=2.1 \times 10^{7} \mathrm{~m}^{3}$ for the 2011 Atakani landslide in Japan (Yamada et al., 2013). Systematic evaluations of landslide characteristics based on seismic recordings are also given by Chen et al. (2013).

If all these calculations were done automatically, within minutes from the event, the authorities would have received a detailed alarm report containing the coordinates and magnitude of the landslide, the runout, the rock/soil involved, the volume and impact velocity, the number of people and infrastructure potentially affected, and the estimated damage. Such quantitative information can be extremely useful for launching the rescue operations in the most efficient way. Some work has been done on this path already (Chao et al., 2017), and so far it seems very promising.

Finally, after the landslide event, an accurate and continuous secondary hazard assessment is fundamental. Fan et al. (2017) reported on a preliminary evaluation of the secondary hazard deriving from potential further failures in the source area and its surroundings. Various potentially unstable masses have been identified. Among them, a large-scale deformation of a 4.5 million $\mathrm{m}^{3}$ mass was detected through 
the interpretation of UAV images. The mass was likely displaced by the shearing and dragging action of the Xinmo landslide, but it stabilized after sliding for about $40 \mathrm{~m}$ after encountering a natural obstacle. During the emergency rescue operations, the mass was believed to be in a state of incipient failure and received considerable attention. In order to provide a reliable evaluation of its stability condition, and to ensure the safety of people near the landslide deposition area and preventing further disasters, a ground-based SAR was installed. Subsequently, numerical modelling with various methods (finite elements, discrete elements) was carried out to evaluate the potentially affected areas in case of a new failure (Scaringi et al., 2017). The model results showed that the potential new landslide would likely affect several more buildings and a further portion of river and of road infrastructure. Furthermore, the resulting river damming would pose a serious risk for the population living downstream in the case of dam breach and for the population living upstream with the possible water level rise. In the wake of these results, different modelling approaches have been discussed comparatively, and the opportunity of an integrated real-time monitoring-and-modelling system arose. As pointed out by Molinari et al. (2014), a physically based numerical model capable of re-computing a new solution in a very short time (i.e. within seconds) based on spatially distributed real-time field monitoring data can be extremely useful in dynamic risk assessment systems at a scale of detail to provide early warning to the authorities and implement timely risk mitigation countermeasures.

\section{Concluding remarks}

The Xinmo tragedy taught us a tough lesson, but it also showed us how the use of new technologies and the collaborative work of experts and professionals can prove successful in identifying potential hazards and performing quick assessments in "inaccessible" areas. As the hazard chain of earthquakes can last for centuries, we argue that a dedicated hazard prevention and mitigation department should be established in every region where strong earthquakes can strike. It would provide the necessary coordination and integration of resources, information, equipment, and labour. It would be able to set up big data centres and platforms, automatic reconnaissance, and warning and alarm algorithms. It would carry out comprehensive research on geological hazard prevention and promote the practical application of new technologies. Finally, it would comprehensively enhance our capacity to prevent and mitigate geological hazards, as well as avoid tragedies.

Data availability. No data sets were used in this article.
Competing interests. The authors declare that they have no conflict of interest.

Acknowledgements. After the occurrence of the 24 June Xinmo landslide, the State Council, the Ministry of Land and Resources, and various governmental departments at all levels in Sichuan Province immediately devoted their efforts to emergency rescue operations, secondary hazard relief, and geological surveying and monitoring. To them go our most sincere appreciation and gratitude.

We thank the Sichuan Provincial Surveying and Mapping Geographic Information Bureau, the High-resolution Earth Observation System Sichuan Data and Application Center, the Sichuan Shu Tong Geotechnical Engineering Company, and the Beijing Digital Greenfield Technology Co. Ltd. We express our gratitude to Yueping Yin from China Geological Environment Monitoring Institute, to Xiao Li from China Geological Survey; to Zhenhong Li from Newcastle University, to Lu Zhang and Mingsheng Liao from Wuhan University; to Qin Zhang from Chang'an University; to Shizhong Hong from Chengdu Earthquake Prevention and Hazard Mitigation Bureau; to Xinghui Huang from China Earthquake Networks Center; to Yong Li from Chengdu University of Technology; and to Chong $\mathrm{Xu}$ from the Institute of Geology, China Earthquake Administration, for providing valuable information at the earliest time. We express sincere thanks to Yanan Jiang, Jing Ran, Xianxuan Xiao, Weiwei Zhan, Jing Ren, Yuanzhen Ju, Chen Guo, and other postgraduate students from Chengdu University of Technology for their hard work on the UAV aerial photography, ground-based SAR monitoring, and other field work.

This research is financially supported by National Science Fund for Outstanding Young Scholars of China (grant no. 41622206), the Funds for Creative Research Groups of China (grant no. 41521002), National Science Fund for Distinguished Young Scholars of China (grant no. 41225011), the Fok Ying-Tong Education Foundation for Young Teachers in the Higher Education Institutions of China (grant no. 151018), the AXA fund, and the Fund from Land and Resources Department of Sichuan Province (grant no. KJ-2015-01).

The authors are grateful to the editor, Kang-tsun Chan, for handling the manuscript, and to Wei-An Chao and one anonymous referee for the useful comments and for encouraging the publication of this work.

Edited by: Kang-tsung Chang

Reviewed by: Wei-An Chao and one anonymous referee

\section{References}

Agioutantis, Z., Kaklis, K., Mavrigiannakis, S., Verigakis, M., Vallianatos, F., and Saltas, V.: Potential of acoustic emissions from three point bending tests as rock failure precursors, International Journal of Mining Science and Technology, 26, 155-160, https://doi.org/10.1016/j.ijmst.2015.11.024, 2016.

Behm, M.: Feasibility of borehole ambient noise interferometry for permanent reservoir monitoring, Geophys. Prospect., 65, 563580, https://doi.org/10.1111/1365-2478.12424, 2016.

Chao, W.-A., Wu, Y.-M, Zhao, L., Chen, H., Chen, Y.-G., Chang, J.-M., and Lin, C.-M.: A first near real-time seismology- 
based landquake monitoring system, Sci. Rep. UK, 7, 43510, https://doi.org/10.1038/srep43510, 2017.

Chen, C.-H., Chao, W.-A., Wu, Y.-M., Zhao, L., Chen, Y.G., Ho, W.-Y., Lin, T.-L., Kuo K.-H., and Zhang, R.-M.: A Seismological Study of Landquakes Using a Real-Time Broadband Seismic Network, Geophys. J. Int., 194, 885-898, https://doi.org/10.1093/gji/ggt121, 2013.

Cheng, G., Wang, X., He, X., Fan, J., and Fan, J.: Outburst Risk of Barrier Lakes in Sichuan, China, J. Mt. Sci., 5, 189-193, https://doi.org/10.1007/s11629-008-0208-7, 2008.

Chinese Government: China's Actions for Disaster Prevention and Reduction, available at: http://english1.english.gov.cn/ official/2009-05/11/content_1310629.htm (last access: 25 January 2018), 2009.

Crosetto, M., Monserrat, O., Luzi, G., Cuevas-Gonzáles, M., and Devanthéry, N.: Discontinuous GBSAR deformation monitoring, ISPRS J. Photogramm., 93, 136-141, https://doi.org/10.1016/j.isprsjprs.2014.04.002, 2014.

Daskalakis, E., Evangelidis, C. P., Garnier, J., Melis, N. S., Papanicolau, G., and Tsogka, C.: Robust seismic velocity change estimation using ambient noise recordings, Geophys. J. Int., 205, 1926-1936, https://doi.org/10.1093/gji/ggw142, 2016.

Del Gaudio, V.: Instantaneous polarization analysis of ambient noise recordings in site response investigations, Geophys. J. Int., 210, 443-464, https://doi.org/10.1093/gji/ggx175, 2017.

Di Giulio, G., Cara, F., Rovelli, A., Lombardo, G., and Rigano, R.: Evidences for strong directional resonances in intensely deformed zones of the Pernicana fault, Mount Etna, Italy, J. Geophys. Res.-Atmos., 114, B10308, https://doi.org/10.1029/2009JB006393, 2009.

Fan, X. and Huang, R.: The Landslide Story, Nat. Geosci., 6, 325326, https://doi.org/10.1038/ngeo1806, 2013.

Fan, X., Xu, Q., Scaringi, G., Dai, L., Li, W., Dong, X., Zhu, X., Pei, X., Dai, K., and Havenith, H.-B.: Failure mechanism and kinematics of the deadly June 24th 2017 Xinmo landslide, Maoxian, Sichuan, China, Landslides, 14, 2129-2146, https://doi.org/10.1007/s10346-017-0907-7, 2017.

Hovius, N., Meunier, P., Ching-Weei, L., Hongey, C., YueGau, C., Dadson, S., Ming-Jame, H., and Lines, M.: Prolonged seismically induced erosion and the mass balance of a large earthquake, Earth Planet. Sc. Lett., 304, 347-355, https://doi.org/10.1016/j.epsl.2011.02.005, 2011.

Huang, R.: Some catastrophic landslides since the twentieth century in the southwest of China, Landslides, 6, 69-81, https://doi.org/10.1007/s10346-009-0142-y, 2009.

Lin, C. H.: Insight into landslide kinematics from a broadband seismic network, Earth Planets Space 67, 8, https://doi.org/10.1186/s40623-014-0177-8, 2015.

Lin, C. H., Jan, J. C., Pu, H. C., Tu, Y., Chen, C. C., and Wu, Y. M.: Landslide seismic magnitude, Earth Planet. Sc. Lett., 429, 122-127, https://doi.org/10.1016/j.epsl.2015.07.068, 2015.

Lin, C. H., Kumagai, H., Ando, M., and Shin, T. C.: Detection of landslides and submarine slumps using broadband seismic networks, Geophys. Res. Lett., 37, L22309, https://doi.org/10.1029/2010GL044685, 2010.

Lin, C.-W., Liu, S.-H., Lee, S.-Y., and Liu, C.-C.: Impacts of the Chi-Chi earthquake on subsequent rainfallinduced landslides in central Taiwan, Eng. Geol., 86, 87-101, https://doi.org/10.1016/j.enggeo.2006.02.010, 2006.
Manthei, G. and Eisenblätter, J.: Acoustic Emission in Study of Rock Stability, in: Acoustic Emission Testing, edited by: Grosse, C. and Ohtsu, M., Springer, Berlin, Heidelberg, 239310, https://doi.org/10.1007/978-3-540-69972-9_11, 2008.

Molinari, M. E., Cannata, M., and Meisina, C.: r.massmov: an open-source landslide model for dynamic early warning systems, Nat. Hazards, 70, 1153-1179, https://doi.org/10.1007/s11069013-0867-8, 2014.

Monserrat, O., Crosetto, M., and Luzi, G.: A review of ground-based SAR interferometry for deformation measurement, ISPRS J. Photogramm., 93, 40-48, https://doi.org/10.1016/j.isprsjprs.2014.04.001, 2014.

Nomikos, P. P., Katsikogianni, P., Sakkas, K. M., and Sofianos, A. I.: Acoustic emission during flexural loading of two Greek marbles, in: Rock mechanics in civil and environmental engineering, edited by: Zhao J., Labiouse V., Dudt J.-P., and Mathier J.-F., Proc. ISRM International Symposium - EUROCK 2010, 15-18 June, Lausanne, Switzerland, CRC press, ISBN 9780415586542 , 95-98, 2010.

Okamoto, T., Sakurai, M., Tsuchiya, S., Yoshimatsu, H., Ogawa, K., and Wang, G.: Secondary hazard associated with coseismic landslides, in: Earthquake-Induced Landslides, edited by: Ugai K., Yagi H., and Wakai A., Springer, 77-82, https://doi.org/10.1007/978-3-642-32238-9_8, 2012.

Parker, R. N., Densmore, A. L., Rosser, N. J., De Michele, M., Li, Y., Huang, R., Whadcoat, S., and Petley, D. N.: Mass wasting triggered by the 2008Wenchuan earthquake is greater than orogenic growth, Nat. Geosci., 4, 449-452, https://doi.org/10.1038/ngeo1154, 2011.

Parker, R. N., Hancox, G. T., Petley, D. N., Massey, C. I., Densmore, A. L., and Rosser, N. J.: Spatial distributions of earthquakeinduced landslides and hillslope preconditioning in the northwest South Island, New Zealand, Earth Surf. Dynam., 3, 501-525, https://doi.org/10.5194/esurf-3-501-2015, 2015.

Petley, D. N.: Global patterns of loss of life from landslides, Geology, 40, 927-930, https://doi.org/10.1130/G33217.1, 2012.

Qiu, J.: Listening for landslides, Nature, 532, 428-431, https://doi.org/10.1038/532428a, 2016.

Scaringi, G., Fan, X., Xu, Q., Liu, C., Ouyang, C., Domènech, G., Yang, F., and Dai, L.: Some considerations on numerical methods to simulate past landslides and possible new failures: the case of the recent Xinmo landslide (Sichuan, China), Landslides, accepted, 2017.

Towhata, I.: Long-term effects of earthquake-induced slope failures, Proceedings of the 7th International Conference on Case Histories in Geotechnical Engineering, Chicago 10, available at: http:// scholarsmine.mst.edu/icchge/7icchge/session16/10 (last access: 25 January 2018), 2013.

Wei, X., Chen, N., Cheng, Q., He, N., Deng, M., and Tanoli, J. I.: Long-term Activity of Earthquake-induced Landslides: A Case Study from Qionghai Lake basin, Southwest of China, J. Mt. Sci., 11, 607-624, https://doi.org/10.1007/s11629-013-2970-4, 2014.

Yamada, M., Matsushi, Y., Chigira, M., and Mori, J.: Seismic recordings of landslides caused by Typhoon Talas (2011), Japan, Geophys. Res. Lett., 39, L13301, https://doi.org/10.1029/2012GL052174, 2012.

Yamada, M., Kumagai, H., Matsushi, Y., and Matsuzawa, T.: Dynamic landslide processes revealed by broadband 
seismic records, Geophys. Res. Lett., 40, 2998-3002, https://doi.org/10.1002/grl.50437, 2013.

Yin, Y., Cheng, Y., Liang, J., and Wang, W.: Heavy-rainfall-induced catastrophic rockslide-debris flow at Sanxicun, Dujiangyan, after the Wenchuan Ms 8.0 earthquake, Landslides, 13, 9-23, https://doi.org/10.1007/s10346-015-0554-9, 2016.
Zhang, S., Zhang, L., Lacasse, S., and Nadim, F.: Evolution of mass movements near epicenter of Wenchuan earthquake, the first eight years, Sci. Rep. Uk, 6, 36154, https://doi.org/10.1038/srep36154, 2016. 